an important reference source for further reading in any aspect of the glaucomas. The text is enhanced by many diagrams of good quality and black-and-white photographs which are passable (for they are often reprinted from original articles and lose not only colour but clarity in the transfer). The textbook will join 'Lecture notes' and 'Becker-Shaffer' as one of the three standard glaucoma texts. Every practising ophthalmologist should read one of them. For those requiring the references included here the 'Textbook' is the one to own. ROGER A HITCHINGS

The Myopias. By Brian J Curtin. Pp. 495. US\$75·00. Harper and Row: Philadelphia. 1985.

This work bids fair to become the authoritative source book on the literature of myopia. Written by one whose life-long clinical interest has been in the subject and who has made important contributions to the surgical technique of scleral support, it ranges widely over every aspect of its subject. The commonly encountered myopias are divided into three groups, physiological or correlation myopia without any axial elongation; intermediate myopia, a newish term in which axial elongation is indicated by the presence of a crescent bordering the disc; and pathological myopia, wherein posterior staphyloma is the distinguishing characteristic. The aetiology, pathogenesis, and treatment are considered for each of these groups. Finally the related myopias, as for example those of prematurity or that are drug induced, are reviewed.

As the book is a bringing together of the opinions of many workers in the field both historical and recent, it is not to be expected that the author will come down decisively on the side of some particular standpoint over a controversial issue. The reader should not therefore expect any easy answers to such thorny questions as the predictability of progression, the relevance of close work, the stabilising effect of contact lenses, and other unsettled problems. The encyclopaedic style of the text has indeed reduced what might in some cases have been an appropriate sense of perspective in some sections, where perhaps a little more weight could have been given to the more accepted viewpoints. In spite of this the work must become part of the personal literature of all who are interested in the optical anomalies of the eye.

(1)

\title{
Notes
}

\section{European Ophthalmic Pathology Society}

The 26th Annual Meeting of the Society was held in Peebles, Scotland, on 26-29 May 1987 at the invitation of Professor W R Lee. Dr M S O Tso of Chicago and the Verhoeff Society was the honoured guest. Papers relating to pathological case studies were presented by the 29 attending members and seven invited guests. They were as follows. Ocular manifestations of rabies (A Tarkkanen, Finland). Round cell liposarcoma of the orbit (K Arnesen, Norway). Choroidal metastasis of bronchial carcinoid (E Balestrazzi, Italy). Astrocytoma of the chiasm (M Brihaye, Belgium). Osteoma of the frontal sinus (A Brini, France). Laser photocoagulation of the retina (J Cunha-Vaz, Portugal). Proton-beam irradiated malignant melanoma (B Daicker, Switzerland). Keratoconus posterior circumscriptus (P Donders, Netherlands). Neurothekeoma (?) of the orbit (A Garner, UK). Basal-cell carcinoma of the conjunctiva (G Goder, GDR). Granular cell tumour of the orbit (R Haddad, Austria). Delayed lens-induced inflammation (A Hamburg, Netherlands). Haemangioma of the optic disc (M Hanssens, Belgium). Ocular leishmaniasis in the dog (A Heriques, Spain). Agenesis corneae (O Jensen, Denmark). Neurofibroma in the choroid of a neonate ( $E$ Kock, Sweden) Endophthalmitis haemosiderotoxica (E Landbolt, Switzerland). Bulbar conjunctivitis (G Lang, FRG). Diffuse iris melanoma ( $Z$ Latkovic, Yugoslavia). Photoreceptor atrophy in an infant (W Lee, UK). Degenerative changes in the peripheral retina ( $M$ Matsuyama, Japan). Adeno- 